\title{
Erratum to: Information Systems Design and Intelligent Applications
}

\author{
Suresh Chandra Satapathy, Jyotsna Kumar Mandal, \\ Siba K. Udgata and Vikrant Bhateja
}

\section{Erratum to: \\ S.C. Satapathy et al. (eds.), Information Systems Design and Intelligent Applications, Advances in Intelligent Systems and Computing 435, DOI 10.1007/978-81-322-2757-1_32, 10.1007/978-81-322-2757-1_33}

The book was inadvertently published with an incorrect author's name as Shivalik Mahapatra in Chaps. "A New Block Least Mean Square Algorithm for Improved Active Noise Cancellation" and "An Improved Feedback Filtered-X NLMS Algorithm for Noise Cancellation", whereas it should be Shibalik Mohapatra in both the chapters. The book and the chapters are updated for the same.

The updated original online version for this chapter can be found at DOI 10.1007/978-81-322-2757-1_32

DOI 10.1007/978-81-322-2757-1_33

S.C. Satapathy $(\bowtie)$

Department of Computer Science and Engineering,

Anil Neerukonda Institute of Technology and Sciences, Visakhapatnam, India

e-mail: sureshsatapathy@ieee.org

J.K. Mandal

Kalyani University, Nadia, West Bengal, India

e-mail: jkm.cse@gmail.com

S.K. Udgata

University of Hyderabad, Hyderabad, India

e-mail: udgatacs@uohyd.ernet.in

V. Bhateja

Department of Electronics and Communication Engineering, Shri Ramswaroop Memorial

Group of Professional Colleges, Lucknow, Uttar Pradesh, India

e-mail: bhateja.vikrant@ieee.org 